\title{
NOTAS SOBRE LOS NOMBRES PERSONALES EMBERA
}

\author{
NOTES ON EMBERA PERSONAL NAMES
}

\author{
Sandra Turbay y José Joaquín Domicó ${ }^{2}$
}

\begin{abstract}
Este artículo contribuye a las discusiones sobre la noción de persona entre los indígenas suramericanos a partir del estudio del significado y las funciones de los nombres personales embera del occidente colombiano. Al igual que en otros grupos, hay una fabricación social del cuerpo en un contexto animista y perspectivista. Sin embargo, los embera creen que el cuerpo humano es poroso y logra todo su potencial al asimilar las almas y las cualidades de otras especies durante la infancia. Esta estrecha conexión entre el ser humano y su entorno natural se refleja en los nombres. La mayoría está conformada por palabras compuestas que identifican al nominado con una variedad de seres vivos, accidentes geográficos, objetos y seres espirituales. El lazo entre el nombre y el alma principal del ser humano, junto con el bautizo católico, la pintura corporal y los baños con infusiones de plantas, actúan como defensa frente al ataque de espíritus. Los nombres individualizan a la persona y sirven como marcadores de identidad étnica, además enseñan a los niños y a las niñas valores y cualidades propias de su género.
\end{abstract}

Palabras claves: embera, ontología, onomástica, nombres personales, noción de persona.

This paper aims to contribute to the contemporary debates about personhood in South American indigenous peoples through the study of the meaning and functions of Embera personal names in western Colombia. As in other Amerindian groups, the body is socially fabricated within an animistic and perspectival context. However, the Embera believe that the human body is porous and achieves its full potential by assimilating the souls and qualities of other species during childhood. The Embera proper names reflect the close connection between the human being and their natural environment, and most of them are compound words that identify the person with a variety of living beings, geographical features, objects, and spiritual beings. Furthermore, the link between the name and the main soul of the human being, along with Catholic baptism, body painting, and baths with plant infusions, acts as a defense against the attack of spirits. The Embera names individualize the person, serve as markers of ethnic identity, and teach boys and girls values and qualities of their respective gender.

Key words: Embera, ontology, onomastics, personal names, personhood.

El segundo autor de este artículo era conocido como Karagabí, una deidad embera, cuando colaboró con la primera autora en 1994 en un estudio de impacto ambiental (Duque et al. 1997); sin embargo, sus documentos indicaban que había sido registrado como José Joaquín Domicó y él mismo decía que su nombre embera era Janyama. Una persona podía usar entonces su apodo, su nombre en español o su nombre embera según las circunstancias. Un tiempo después, escribimos la autobiografía del coautor (Domicó et al. 2002), una estrategia metodológica que nos ayudó a mostrar, desde la perspectiva embera, las tensiones propias del matrimonio, el origen de las vocaciones chamánicas, la etiología de la enfermedad, y la manera de negociar la supervivencia con los grupos armados.
Durante los últimos años, la primera autora construyó una base de datos con nombres embera y su traducción al castellano, lo que la llevó a sospechar que tenían alguna relación con las teorías sobre las enfermedades, las prácticas de crianza, la cosmología, las imágenes de género y las relaciones interétnicas. En 2013, aprovechando que el segundo autor estaba viajando a Medellín semestralmente para avanzar en una licenciatura en etnoeducación, analizamos conjuntamente esta lista, a la cual se agregaron los nombres de los habitantes de Chibugadó (Murindó), donde el coautor residía. En julio de 2018 la primera autora tomó un año sabático para asesorar un programa gubernamental de atención a los niños y a las madres gestantes del resguardo embera de Jaikerazabi (Mutatá)

\footnotetext{
${ }^{1}$ Departamento de Antropología, Universidad de Antioquia, Medellín, Colombia. sandra.turbay@udea.edu.co

${ }^{2}$ Miembro indígena embera, comunidad de Chibugado, Departamento de Antioquia, Colombia.
}

Recibido: julio 2019. Aceptado: marzo 2020.

http://dx.doi.org/10.4067/S0717-73562021005000102. Publicado en línea: 10-marzo-2021. 
y así pudo recoger nueva información sobre la relación entre el nombre propio, la concepción de la persona y las prácticas de protección de los niños, y contrastar las traducciones de los nombres propuestas por la misionera Martínez $(1989,1992)$ con las que ofrecía el coautor del artículo y con las que proponían otros embera. El trabajo de campo se extendió entre julio y diciembre de 2018.

Nuestro análisis de la onomástica embera tiene implicaciones para las discusiones sobre la ontología de los grupos amerindios, en tanto permite problematizar algunas generalizaciones que se han hecho sobre la noción de persona y la construcción social del cuerpo en sociedades con sistemas animistas y perspectivistas. El debate sobre estos asuntos parte de los trabajos de Descola (1996) y Viveiros de Castro (1998) que derivaron en lo que actualmente se conoce como el giro ontológico, un enfoque que revalúa la idea de múltiples representaciones culturales sobre un mismo universo, propone alternativas frente al dualismo naturaleza/cultura propio del naturalismo moderno y rescata maneras de concebir la naturaleza que habían estado silenciadas por las visiones antropocéntricas y naturalistas dominantes (Ruiz Serna y del Cairo 2016). Después de su trabajo sobre los achuar de la Amazonía ecuatoriana (1986), Descola (1996) comparó los modos de identificación y relación entre humanos y no humanos en las tierras bajas suramericanas y para ello retomó el concepto de animismo, como idea que imputa a diversos seres no humanos una interioridad idéntica a la de los humanos. Viveiros de Castro (1998) propuso por la misma época una manera distinta de abordar las cosmologías amazónicas, donde él veía era que la definición del otro dependía del punto de vista: los humanos del común (no los chamanes) solamente vemos a los animales y a las plantas como especies naturales desprovistas de subjetividad, igual les pasa a ellas cuando nos ven a nosotros; el autor también destacó la importancia del cuerpo, y no de la interioridad, como elemento diferenciador entre las especies naturales: es el cuerpo el que permite un punto de vista particular, es el cuerpo el que nos hace humanos y no la cultura que es compartida con otros seres vivos (Viveiros de Castro 1998). Desde mucho antes de proponer su teoría perspectivista, Viveiros de Castro había indicado junto con otros autores (Seeger et al. 1979), la necesidad de privilegiar el estudio de la producción social del cuerpo y de la noción de persona. Desde entonces se empezaron a analizar con mayor profundidad los procedimientos culturales que emplean diversas sociedades para individualizar y diferenciar los cuerpos de la misma especie y de otras especies (Tola 2005). En cualquier caso, la asignación de un nombre personal haría parte de ese proceso de construcción del ser humano. Estas etnografías han llevado a contrastar la noción de persona occidental con la de otras culturas usando, por ejemplo, los conceptos de individuo y dividuo: el individuo es una persona indivisible, con un espíritu singular y con una autonomía como actor social, mientras el dividuo es divisible, resultado de un conjunto de partes separadas y actúa como un actor integrado a la sociedad donde desempeña roles culturalmente prescritos (Smith 2012). En esta línea de análisis, Santos Granero (2012) sostiene que, en muchos grupos amazónicos, se piensa que los cuerpos son permeables, que se hallan en permanente flujo, y que están hechos de una variedad de sustancias de origen animal y vegetal, transmitidas a través de actos cotidianos y rituales, que permiten incorporar cualidades físicas y subjetividades deseadas según el género. Vilaça (2011) también llama la atención sobre la naturaleza inestable del cuerpo y su capacidad de transformación, cualidades que estarían relacionadas con una noción de humanidad que incluye tanto a los indígenas mismos como a varios espíritus y animales; la autora explica que la consecuencia de esta noción de humanidad y la localización de la diferencia en los cuerpos es que los indígenas se sienten en peligro de transformarse en animales de otras especies que actúan como predadoras. Más recientemente, Londoño Sulkin (2017) destacó tres características comunes a una gran variedad de culturas indígenas amazónicas: la convicción que el cuerpo es fabricado socialmente; que esto ocurre en un cosmos perspectivista y que las relaciones con los otros de afuera y peligrosos es indispensable; el autor sostuvo además que la reproducción de este "paquete" está ligada al rol central de la moralidad que define imágenes de lo que es un ser humano bueno o admirable.

Un antecedente directo del trabajo que presentamos aquí es el de Losonczy (2006), quien plantea que la asignación del nombre entre los embera dóbida del medio y alto Chocó está relacionada con sus creencias sobre la concepción del ser humano. Los indígenas dicen que cuando se concibe un niño "sube" un muerto anónimo, fallecido de una "buena muerte". Su jaure (alma o principio vital) estaba al otro lado de la tierra y de las aguas gracias a la agonía que había sobrecargado su cuerpo. Del cuerpo en descomposición se desprenden varios jaures, entre ellos uno que es llamado jaure de los huesos que va a formar el esqueleto del niño en el vientre de cualquier mujer, pues los jaures no tienen territorio ni patronímico. Durante el embarazo, el niño va creciendo gracias a la sangre menstrual que la madre ya no expulsa y al semen del padre que copula repetidamente con ella. En cambio, cuando hay muerte súbita el jaure no puede tomar distancia del cuerpo y queda expuesto a la mezcla con sustancias vegetales o animales, razón por la cual terminará convertido en jai, agente de infortunio o instrumento reparador si se incorpora a la tropa de espíritus aliados del chamán (Losonczy 
2006). Afirma Losonzczy que, como hay varios jaures circulando, los embera se ven obligados a observar las circunstancias del nacimiento del niño, su aspecto y su sexo, para determinar la identidad del jaure entre las plantas y animales silvestres. Este reconocimiento lo hacen las mujeres mayores que presiden los ritos de acogida del recién nacido. Los nombres de los niños vienen, en esa región del Chocó, del universo animal $\mathrm{y}$ vegetal, mientras los apellidos son los mismos que impuso Karagabí, el Creador, para prevenir el incesto (Losonczy 2006). El nombramiento del niño a partir de la observación de su comportamiento es un primer paso en la construcción de la identidad, pero el individuo puede sufrir muchos cambios en sus características funcionales dominantes a lo largo de su vida. En esos casos, se da una reestructuración de los jaures o se produce la entrada de uno distinto y el individuo puede asumir un nuevo nombre dotado de eficacia simbólica (Losonczy 2006).

Nuestros hallazgos revelan tres rasgos de la onomástica embera eyábida: que el nombre no expresa una alteridad radical del ser humano frente a otras especies o entidades, sino un acto simbólico de identificación con una variedad de seres vivos, accidentes geográficos, objetos y seres espirituales; que la desagregación póstuma del cuerpo libera las almas y permite que alguna de ellas regrese bajo la forma de un niño por nacer, de ahí que no sea raro buscar entre los nombres de los difuntos los nombres para los recién nacidos; y que el acto de nombrar tiene funciones similares a las de la pintura corporal, el ritual llamado nẽpoa, los baños con infusiones de flores y el bautizo católico: se trata de dotar al niño o a la niña de la belleza, las destrezas y las habilidades propias de su género, de hacerlo invisible frente a los espíritus malignos y de cerrar su cuerpo frente a agresiones chamánicas.

\section{Una Perspectiva Etnológica del Nombre Personal}

Este artículo se inscribe en una tradición académica que analiza el valor simbólico y semántico de los nombres, su relación con la cosmología, los sistemas de parentesco, los procesos de constitución de la persona, la identidad social y las diferentes formas de individuación y de temporalidad (Bodenhorn y vom Bruck 2006; de Matos Viegas 2008). Un breve examen de algunas funciones de los nombres personales en grupos indígenas suramericanos ilustrará estos asuntos y servirá de punto de partida del análisis de la onomástica embera.

En primer lugar, el nombre tiene la función de individualizar o clasificar al sujeto. Los nombres individualizantes tienden a aludir a las cualidades del nominado o a anécdotas de su viday suelen ser exclusivos mientras los nombres clasificatorios remiten a un orden social, están ligados a los grupos a los cuales pertenece la persona, se vinculan a posiciones sociales fijas que los individuos pueden ocupar en algún momento de su vida, replican alguna generación anterior o indican un tipo de relación de parentesco. En algunas sociedades el nombre tiene una función más individualizante y en otras una función más clasificatoria; por ejemplo, entre los tupinambás predominan nombres singulares e irrepetibles (de Matos Viegas 2008), mientras entre los tikuna el niño recibe un nombre que responde a las características clánicas (Goulard 1994). Viveiros de Castro (1986) identificó dos conjuntos de onomástica con base en la oposición exonomia-endonimia: en el primero, los nombres y las identidades vienen del exterior de la sociedad, la muerte y la alteridad son directamente constitutivas de la persona y los nombres tienen una función individualizadora; en el segundo, los nombres y las identidades vienen de adentro, designan relaciones sociales, se transmiten entre los vivos, son esenciales para la continuidad social y tienen una función clasificatoria. Sin embargo, un nombre puede individualizar y clasificar al mismo tiempo, como ocurre con los nombres mapuche que aluden simultáneamente al territorio, al linaje y a una característica particular del individuo nombrado (Szulc 2012). Ya desde 1992, Gonçalves (1992) había puesto a prueba la tesis de Viveiros de Castro (1986) comparando los sistemas de nominación en 27 grupos indígenas de las tierras bajas suramericanas y concluía que la individualización y la clasificación no eran excluyentes, sino que estaban repartidas de manera desigual. Vanzolini (2019) hace un planteamiento similar al analizar la onomástica aweti del Alto Xingu, encontrando que los nombres pueden ser entendidos como mediadores entre la continuidad, al marcar la identidad y la mutua dependencia entre parientes que comparten los mismos nombres, y la diferenciación, producida por los efectos que nombres específicos pueden tener en la gente, por ejemplo, si uno recibe el nombre de un jefe debería actuar como tal; se trata de una sociedad donde los bebés reciben al nacer los nombres de algún abuelo o abuela, pero cuando a las niñas les llega la pubertad o cuando a los niños les perforan las orejas, los cambian por nombres abandonados por la muerte de sus poseedores.

En segundo lugar, el nombre propio tiene una función denotativa (señala a alguien) y, eventualmente una función connotativa (dice algo de alguien). Los nombres estrictamente denotativos no significan nada y tienden a ser estables, pero los nombres con una función connotativa pueden cambiar para ser compatibles con los rasgos de personalidad, con las características físicas o con la función social que desempeña la persona en un momento dado de su vida. Los apodos son nombres con función connotativa asignados generalmente por pares en el marco de relaciones jocosas, como ocurre entre 
los grupos tukano del noroccidente amazónico donde todas las personas tienen al menos un apodo referido a un mamífero, un pájaro o a un pez que describe el carácter, los hábitos o la apariencia del portador (HughJones 2002).

En tercer lugar, el nombre puede tener una función referencial o una función vocativa. En otras palabras, uno puede hablar de alguien o dirigirse a alguien mencionando su nombre, aunque en algunas sociedades se usa más el término de parentesco como vocativo, o se restringe la función referencial del nombre si se va a hablar de una persona fallecida. Los desana (un grupo tukano) dejan de usar los nombres propios como vocativo a partir del ritual de iniciación y lo sustituyen por un término de parentesco, como si a partir de ese momento el joven debiera estar siempre consciente de los lazos que lo unen a otros miembros del grupo (Reichel-Dolmatoff 1986). Como en algunas comunidades una persona puede tener varios nombres, es necesario explorar el protocolo que indica cuál nombre se debe usar en cada circunstancia; por ejemplo, entre los tukano un individuo tiene al mismo tiempo un nombre de espíritu, que es sagrado, secreto, conocido solamente por las personas más íntimas y que únicamente se usa en discursos rituales, un apodo que se emplea cotidianamente como vocativo por parientes y amigos y, un nombre colombiano o brasilero para relacionarse con los blancos (Hugh-Jones 2002). Los ya mencionados aweti prohíben pronunciar los nombres de los afines y con frecuencia se dirigen a los parientes por su apodo o por su nombre "de blanco" y no por el nombre de familia (Vanzolini 2019).

En cuarto lugar, el nombre puede tener la función de producir personas, garantizar la perpetuación de las almas de los difuntos, proteger el alma o la fuerza vital de la persona, producir cualidades o disposiciones, humanizar al recién nacido y darle un papel dentro de su comunidad. La etnografía de Cayón (2013) sobre los makuna, que son también un grupo tukano, ilustra con detalle el lazo entre el nombre, el alma y la salud de los recién nacidos. El autor explica que los bebés reciben ritualmente un nombre que depende de la profesión que va a tener y que ese nombre pertenece a alguno de los hijos e hijas de Anaconda de Agua o a los nombres masculinos o femeninos usados exclusivamente por su grupo. La "curación" es la que hace humana a cada persona y está a cargo del chamán, es él quien va a recorrer mentalmente los diferentes lugares míticos y sagrados del territorio para visitar distintas malocas invisibles donde el bebé es presentado a sus dueños con el fin de recibir protección y defensa. Por su parte, los kubeo yuriwawa tienen apenas 11 nombres masculinos y 12 femeninos, dentro de los cuales los abuelos escogen aquellos que llevarán sus nietos; esos nombres estabilizan el alma, son responsables del adecuado crecimiento de la persona, marcan su posición dentro de una jerarquía y propician el desarrollo de ciertas habilidades y capacidades; así, por ejemplo, si alguien recibe el nombre de un poderoso payé, se espera que sea un gran conocedor (Pedroso 2019).

Los grupos étnicos están inscritos en sociedades nacionales donde ocupan una posición subordinada, por eso es importante examinar cómo se ajustan los sistemas de nominación tradicionales con las exigencias que los Estados hacen para el registro de los recién nacidos. Entre los Mai-Huna, por ejemplo, hay una tendencia a practicar la endogamia clánica que Bellier (1994) atribuye a la superposición de los apellidos de origen español sobre los nombres de los clanes, pues así, cuando un individuo se casa con alguien que posee un patronímico distinto, tiene el sentimiento de no pertenecer a una misma familia.

Para analizar el sistema de nominación embera hemos dividido este artículo en cuatro partes. En la primera describiremos al grupo embera, en la segunda expondremos cómo se construyen los nombres y cuál es su significado, en la tercera analizaremos su uso y en la cuarta indicaremos la relación del acto de nominación con otros rituales de protección de los niños y las niñas.

\section{Los Embera}

En el 2005 había en Colombia 70.000 embera (DANE 2005), ubicados en las selvas del Pacífico y en la Cordillera de los Andes. En Panamá, los embera viven en la provincia del Darién, donde fue creada la Comarca Emberá-Wounáan en 1983 (Herrera 2012; Kane 1994; Kondo 2016); en 2010 había 9.544 embera y wounáan en esta comarca (Rodríguez et al. 2015). El nombre embera, que es el que los indígenas usan para referirse a ellos mismos, significa gente: embera dóbida (gente de río), embera eyábida (gente de montaña) y embera chamí (gente de la región del Chamí). La literatura etnográfica usaba hasta hace poco tiempo los nombres de chocóes, katíos y chamíes para referirse a los dóbida del departamento del Chocó, a los eyabida del occidente del departamento de Antioquia y a los chamíes del departamento de Risaralda. Loewen (1963) empleó el término chocó para referirse a todas las lenguas habladas por los embera distribuidos a lo largo de Panamá, Colombia y Ecuador. Se trata de lenguas con un tronco común que se han diferenciado hasta el punto de que, si se encuentran indígenas de distintos grupos en una reunión, prefieren usar el español como lengua franca.

El asentamiento es disperso, aunque en algunos lugares se han formado aldeas alrededor de las escuelas. En las selvas del Pacífico, subsisten de la caza, la pesca y la horticultura, mientras en los municipios andinos, la caza y la pesca ocupan un lugar marginal y es frecuente 
el trabajo en fincas cafeteras y ganaderas. Este artículo se refiere a los embera eyábida o de montaña que viven en la vertiente occidental de la Cordillera Occidental de los Andes, especialmente a los indígenas que viven en las cabeceras de los afluentes del Río Atrato en el municipio de Murindó y a los indígenas que están en el municipio de Mutatá sobre la parte alta de la cordillera. Aparentemente los embera de las selvas de Murindó preservan un modo de vida más tradicional que los embera cordilleranos de Mutatá. Es cierto que estos últimos han sido desplazados de su territorio, que viven en un pequeño resguardo a orillas de la carretera, que tienen un asentamiento nucleado alrededor de una escuela, y que mandan a sus hijos a estudiar en el liceo de la cabecera municipal junto a jóvenes mestizos, pero eso no significa que sean menos "auténticos". Existen muchas maneras de ser embera $y$, ajustarse a las demandas del entorno es un modo de garantizar la supervivencia como grupo étnico. Así mismo, el aislamiento, el monolingüismo y la economía de subsistencia de las tierras bajas no son indicadores de conservación de la cultura, sino expresiones del confinamiento al que los grupos armados han sometido a las comunidades.

\section{Construcción y Significado de los Nombres Personales}

En lengua embera existen nombres simples y compuestos; los primeros están formados por una sola base nominal mientras los segundos unen dos bases simples para expresar un nuevo concepto con un solo acento principal. Esta lengua es aglutinante porque junta muchos conceptos en una palabra (Aguirre et al. 2013). Este rasgo les permite formar nuevas palabras a partir de elementos linguísticos familiares. Por ejemplo, domé, que es el nombre de la escalera hecha de un palo con muescas por la que se sube a la vivienda construida sobre pilotes, es una palabra compuesta por $d o$ : río y $m e$ : pene, como si la escalera fuera un pene del río (Isacsson 1993). Se debe tener en cuenta que existen variaciones en la pronunciación de la lengua embera y que los hablantes las explotan conscientemente con fines semánticos ${ }^{2}$.

En esta investigación identificamos cuatro conjuntos de nombres. El primero incluye nombres sin significado pero que tienen un valor sonoro. Estos se escogen entre los nombres conocidos o se inventan conservando alguna raíz común Neiyipuma y Neider (nombres de una mujer y de su hermano). Esa afición por modificar nombres conocidos para crear nombres nuevos se aplica tanto a nombres embera como a nombres en castellano, por ejemplo Leonardo y Leoicardo (nombre de un hombre y su hermano).

El segundo conjunto incluye nombres de animales, de plantas, de objetos manufacturados o de fenómenos naturales: Betá es pescado, Inguepono es una flor, Chirurú es flauta, y Euma es arco iris.

El tercer conjunto de nombres es el de los apodos, que muchas veces terminan desplazando al nombre oficial de la persona, como un niño de las tierras altas a quien todo el mundo conoce como Orropí, porque estuvo tan desnutrido que se le veían las costillas (Orroa).

El cuarto conjunto de nombres, ampliamente mayoritario, está compuesto de lexemas y gramemas. Los lexemas son palabras que denotan seres o entidades y acciones o sucesos, mientras los gramemas son palabras gramaticales que indican cambios o accidentes de esas entidades (sustantivos) o sucesos (verbos) (Aguirre et al. 2013). En los nombres recogidos se repiten algunos lexemas que aparecen al principio del nombre como $c h a=$ caña, $d o=$ río; jai= enfermedad, espíritu o esencia y je= serpiente. Se trata de palabras con existencia léxica independiente, que con frecuencia remiten a la mitología o a la cosmología embera, como veremos adelante. Los gramemas más frecuentes son:

-El partidor chi, como en Chindau (estrella, literalmente el ojo: $c h i d a b u$ ), que la gente interpreta como gusano cuando se presenta independientemente.

-El generalizador ne, como en Nepono (cualquier flor) o Nebapuma (cualquier caldo).

-El declarativo ma usado por ejemplo en el nombre Tobiama (de To/do=nacer, parir; bia: bien).

-El interrogativo zamá que figura por ejemplo en el nombre Dozamá o Dochamá: (¿dónde está el riachuelo?).

-Como gramema, Bi se suele sufijar a las raíces verbales para indicar "dejar hacer algo" (Aguirre Licht 2014) y en los nombres indica género masculino, como en Jaibí. Sin embargo, Bi es también un lexema que significa barriga y, constituye una variante en la pronunciación de la palabra be, que significa maíz. Isacsson (1993) ha mostrado que el maíz, be, es un principio germinal de carácter masculino, que los peces son el maíz del río de abajo -betá, de be: maíz y ta: semilla)- y que los seres humanos son embera, es decir gente de maíz o los peces del mundo intermedio pues bera es una variación en la pronunciación de betá (pez) y de birá, bidá, sufijos que aparecen frecuentemente en las denominaciones tribales del Chocó.

-Puma, que no significa nada aisladamente pero que, añadido a un nombre, indica género femenino, como en Jaidipuma. En la vida cotidiana, puma se puede obviar pues ya se sabe que estamos frente a una mujer y, en vez de decir Nakipuma, se dice Naki a secas.

Podríamos pensar que los lexemas que aparecen en los nombres propios tienen una función referencial, que denotan una cosa externa o un concepto con un significado unívoco, pero cuando se le pide a alguien que explique el significado de su nombre, la respuesta 
más frecuente es que no sabe. Si uno insiste, entonces el interlocutor segmenta el nombre y traduce cada uno de los lexemas que lo componen y que designan acciones como crecer, andar, besar, saludar, pisar, morder, entregar, montar o nacer; partes del cuerpo como ojos, cabeza, espalda, dientes o pie; objetos manufacturados como canasto, harina de maíz, sopa o vestido; cualidades como bonito, bueno, colaborador o trabajador y elementos naturales como río, arroyo, viento, arco iris, bosque, flor, hoja, perfume, oro, águila, armadillo, tórtola o serpiente. Estos lexemas se repiten en muchos nombres, pero combinados de distinta manera.

Las traducciones que Martínez $(1989,1992)$ hace de los nombres aluden a condiciones, habilidades o cualidades de la persona nombrada: buen curandero, la que enamora, el andariego, niña hermosa, el que guía, la de ojos puros, etc. Cuando un embera se arriesga a proponer, de entrada, un significado general de un nombre, este no coincide necesariamente con la traducción literal del nombre o con la justificación de su escogencia ofrecida por los familiares del nominado. La persona que escucha el nombre necesita conocer la historia familiar del portador del nombre para comprender plenamente su sentido.

El significado del nombre no resulta de sumar los significados de las palabras que lo forman, sino de un contexto significante. Las palabras que componen el nombre son apenas el punto de partida de la interpretación. Dicho de otro modo, el valor semántico del nombre se deriva, en parte, de las asociaciones que los embera establecen entre las palabras que hay en el nombre, la historia particular de la persona nombrada, las características conocidas de las especies naturales y de su entorno, las narraciones chamánicas y los relatos míticos. La función referencial de las palabras incluidas en el nombre se ve opacada por la función indexical del nombre completo, que requiere, para una interpretación exitosa, que el hablante conozca al portador del nombre. Una mujer había llamado a su hija Eniuma, porque le recuerda la palabra euma: arco iris y explicaba la elección diciendo que la niña era inquieta como una ardilla que salta de un árbol a otro formando arcos; otra mujer había llamado a su hijo Jaidodibi, porque ese nombre une las palabras espíritu: jai y río: $d o$, y a ella le parecía que era como si uno estuviera buscando algo en un riachuelo, sin embargo, otra mujer traducía ese nombre como: "el que está curando". La hermana Martínez (1992) registra el nombre Tobiama, y lo traduce como "el que es eterno", pero literalmente to/do significa río o parir, y bía significa bueno.

Es cierto que algunos nombres compuestos no dejan lugar a dudas sobre su significado. Por ejemplo, Jaibiama, (jai: enfermedad o espíritu; bia: bueno), es traducido unánimemente como "espíritu bueno". El lexema Jai está presente siempre en posición inicial, en nombres masculinos o femeninos. En el Censo Indígena de Murindó figuran 473 nombres en lengua embera, de los cuales 83 empiezan con el lexema jai (Gobernación de Antioquia 2014). El espíritu o jai está en el mundo exterior y se comunica con el chamán, a diferencia del alma o jaure, que está dentro del sujeto y no habla. Sin embargo, la distinción entre las dos entidades no es tan simple: el chamán puede encerrar dentro de su cuerpo a sus jais aliados utilizando la palabra (Losonczy 1984) y las almas pueden transformarse en jais después de la muerte de su poseedor.

El tema de los maleficios aparece recurrentemente en las conversaciones cotidianas, pues casi toda enfermedad o desgracia es atribuida a los espíritus enviados por los enemigos ${ }^{3}$. El conflicto armado y el desplazamiento forzado han incrementado la sensación de zozobra, de indefensión, de confinamiento, de desintegración de las parentelas, de incertidumbre y de desarraigo y han exacerbado las acusaciones de hechicería. En este contexto, la figura del jaibaná cobra una importancia excepcional pues exalta los lazos comunitarios, controla los males enviados por otros chamanes, garantiza el éxito de la caza, la pesca y la agricultura, encierra a los espíritus peligrosos para que las personas desplazadas puedan ocupar nuevos territorios, restablece la salud de sus pacientes y da seguridad a las familias para enfrentar las adversidades.

Daremos dos ejemplos adicionales del uso del lexema jai en los nombres. El primer nombre es Jaichididau, interpretado por uno de nuestros entrevistados como una referencia específica a los ojos claros, hermosos o con capacidad de ver más allá de las apariencias y hallar la causa de las enfermedades (daw) dabu/tau: ojo). Según él, cuando los chamanes creen que sus hijas nacen con habilidad para curar a través del sueño, les ponen nombres como Jaidau, Jaikinindau o Jaichididau. De hecho, las personas mayores usan la palabra daubaná, en vez de jaibaná, para referirse al chamán, porque él ve los espíritus en sus sueños ( $d a b u$ o tau es ojo). El segundo nombre es Jaitzarichuma, (jai: espíritu o enfermedad; chuma: duro), su portadora nos decía que gracias a su nombre ella era resistente a cualquier maldad que le quisieran hacer. Podemos decir entonces que el hecho de llevar nombres con la palabra jai expresa una identificación positiva con la entidad espiritual y algún grado de dominio sobre ella, pero en ningún caso constituye un riesgo para el sujeto, porque los espíritus solamente son peligrosos si están fuera de control, si vagan libremente, si no tienen un amo, o si entran en el cuerpo de una persona por orden de un chamán.

El lexema do, que significa río, aparece en la toponimia del occidente de Colombia y en muchos nombres masculinos como Doerubi o Dokibizá, y 
femeninos como Dobiapuma y Dochiditau. El río es muy importante en la vida cotidiana y en la mitología embera. Isacsson (1993) resalta que los embera se bañan varias veces al día en el río, que se sumergen en sus aguas cuando se enferman, cuando les llega la primera menstruación, cuando dan a luz y cuando muere algún pariente, siempre pensando que así purifican su cuerpo y restauran la fuerza perdida. Las mujeres dan a luz en el río, lavan allí la ropa, arreglan el pescado y las presas de caza y conversan con otras mujeres mientras los niños juegan alrededor. En las cabeceras de los ríos se producen además encuentros misteriosos con la gente que vive en el mundo inferior o con los dueños sobrenaturales de las plantas y los animales. Los nombres que incluyen el lexema $d o$, recuerdan entonces al río, a las propiedades de sus aguas y a los seres que lo habitan.

El lexema $J e$ aparece en posición inicial en varios nombres masculinos, como Jechidiama, Jebarsábi, Jenanimbi, y femeninos como Jechauma y Jeneguidau. También aparece en el nombre de una hormiga, Jentzerá, que escondía el agua en el árbol jenené: el mito cuenta que el dios Karagabí tuvo que cortar este árbol para liberar el agua y formar los océanos y los ríos (Isacsson 1993). El nombre de la boa es Jepá y a ella se le atribuye el movimiento de las aguas del río. Isacsson (1993) sostiene que los embera del departamento del Chocó se identifican con la boa y que perciben su propio cuerpo como un cosmos binario compuesto por el río subterráneo y el espacio celeste. Los embera del departamento de Antioquia dicen que las culebras eran antiguamente personas que dominaban el veneno y que el jaibaná las escogió como "parte de su familia" porque rejuvenecen cambiando de piel. El espíritu de culebra es uno de los más poderosos y, cuando alguien quiere tenerlo, se pinta el cuerpo con motivos de culebra y talla bastones de madera con los diseños de su piel (Domicó et al. 2002). En suma, los nombres que incluyen el lexema je, aluden a las serpientes, al agua y al revujenecimiento.

Los nombres son el resultado de una combinatoria infinita del repertorio lingüístico embera, lo cual ayuda a crear nuevos nombres variando apenas una sílaba de un nombre ya conocido. De este modo se logra cumplir con la regla de no repetir nombres de personas vivas y se conserva la carga semántica asociada a la palabra que sirve de núcleo generador. Para dar solamente un ejemplo, hallamos nombres como Erukiapuma, Erubilia, Erubicia, Erubiapuma, Eruchipuma, Erubiama, Eruchiduau, Erunibi y Erubipuma, todos ellos derivados de eru, que significa raya o línea.

El nombre embera con carga semántica no se refiere simplemente a una cosa exterior, tampoco se limita a describir al sujeto que lo porta. El nombre está cargado de fuerza para cambiar el aspecto físico y las cualidades morales del niño o de la niña o para generar un entorno positivo para su desarrollo. Una mujer llamó a una hija Inguepuma para que fuera tan bonita y alegre como el pájaro Ingue; para otra de sus hijas escogió el nombre Baepono, porque esa es una flor que da buena energía, quita el sueño, da buena suerte para el marido y para el trabajo y evita que la envidien; su nieta de tres años lleva el nombre de la flor Arizapono, para contrarrestar su fealdad, ella espera que su futuro marido la encuentre bonita y no la abandone y que la gente diga que es una niña "linda, formalita y de buen corazón". Los baños con infusiones de estas flores, refuerzan la acción del nombre, para ello se macera la planta la víspera de luna llena y se le aconseja: "porque la planta es embera y escucha; yo le digo: mañana voy a bañar con esto, la gente me va a querer, no se van a burlar, los novios me van a querer, esa persona no va a hablar de mí, ese hombre me va a dar plata, le va a dar regalo a mi mamá" (Mujer de Jaikerazabi).

Es frecuente escuchar que el jaibaná puede ver a los animales y las plantas como gente y hablar con ellos durante sus sueños, también dicen que en los bosques de las cabeceras de los ríos están los dueños o wandras de las especies naturales y que pueden resultar peligrosos para quienes se aventuran por esos parajes. Esos seres sobrenaturales, ya se trate de dueños de especies o de "fieras" con figura humana, no son buenos o malos en sí mismos, su comportamiento frente a los intrusos dependerá de si hubo o no una negociación onírica previa por parte del jaibaná. Como dice Londoño Sulkin (2017), relacionarse con los otros peligrosos es necesario. En el caso embera, esa relación se establece para dar belleza, buenos sentimientos y habilidades a los niños y a las niñas, para que las poblaciones animales se multipliquen y la cacería sea fructífera y para que el jaibaná pueda recibir durante sus sueños los secretos medicinales de las plantas, en cualquier caso esa relación debe basarse en un principio de reciprocidad (RosiqueGracia et al. 2020).

El repertorio de apellidos embera es distinto al de los nombres personales y es muy limitado. Los más frecuentes en los censos son Domicó, Sinigüí, Bailarín, Carupia, Majoré, Cuñapa, Zapia y Guaseruca. Estos apellidos aparecen en los registros civiles y son un indicador de etnicidad porque, a diferencia de otros grupos indígenas colombianos, los embera no adoptaron apellidos españoles. Dentro de una comunidad pequeña sirven para identificar la pertenencia a una familia, pero en el macroterritorio embera son demasiado comunes y muchas personas que no tienen ningún parentesco conocido llevan el mismo apellido.

El estudio del sistema de nominación embera no se agota en el análisis del significado de los nombres. Es cierto que Isacsson (1993) encontró en la etimología una exitosa vía de acceso al pensamiento simbólico de 
los embera, pero su énfasis en el simbolismo y en la ontología le impidió contextualizar la vida social embera en el marco de las dinámicas regionales. Un análisis del significado relacional de los nombres propios requiere ir más allá del plano de la lengua y nos obliga a explorar como esta se expresa en el plano del habla y como los elementos estructurales del pensamiento embera se ajustan a las constricciones que impone la sociedad mayoritaria. Por esta razón expondremos a continuación, la manera como se usan los nombres en las dos comunidades estudiadas.

\section{Escogencia y Uso del Nombre}

Anteriormente el niño o la niña recibía su nombre cuando tenía unos ocho meses, pero ahora son registrados después del nacimiento para poder gozar de los servicios de salud y de los subsidios estatales. En Colombia las personas llevan dos apellidos, primero el paterno y luego el materno, pero entre los emberá es muy común que la madre vaya sola a la registraduría y por eso el niño o la niña queda con sus dos apellidos. A veces la pareja no ha escogido el nombre y pide sugerencias al registrador o a una enfermera del hospital, que sugiere entonces un nombre en castellano. Algunos niños y niñas son registrados con nombres diminutivos: Manuelito, Justico, etc., aunque los registradores tratan de impedirlo explicando que el niño no se va a quedar pequeño toda la vida; los embera traducen así el diminutivo zake, que usualmente aplican a los nombres de los bebés. Muchos niños son registrados con nombres que pertenecieron a parientes fallecidos y, en todo caso, no admiten homónimos contemporáneos. No ponen nombres de personas vivas alegando que no quieren tener tocayos, a diferencia de otros grupos de las tierras bajas suramericanas que escogen precisamente el nombre de una persona conocida con quien el niño compartirá su subjetividad, al menos durante el primer año de vida (Santos-Granero 2012).

Antes de 2015, no había un sistema informático unificado en la Registraduría Nacional y se permitían registros nuevos de personas mayores. Los embera aprovechaban para registrarse nuevamente ellos mismos o para registrar a sus hijos con otro nombre o con otro apellido, por eso algunos tienen hasta tres registros en municipios distintos. A veces los cambios se hacían por gusto y a veces para quitarle de hecho la patria potestad al cónyuge después de una separación, pues en adelante su hijo tendría otra identificación.

Algunos ancianos comentaron que antiguamente los nombres se seleccionaban para que no se acabaran los nombres de los parientes que habían sido trabajadores ágiles, buenos pescadores, buenos cazadores y de buen corazón, ya fueran del lado paterno o materno. También dijeron que era común que las personas llevaran nombres de animales. Llamaban tigre a alguien que era buen cazador; venado a alguien que corría mucho, o conejo a alguien que era mentiroso. Algunas mujeres contaron que habían puesto a sus hijos el nombre de algún animal del que habían tenido antojo durante el embarazo. Otros autores que han trabajado con embera dóbida del Chocó y de Panamá también han dicho que a los niños y a las niñas todavía les ponen nombres de especies naturales (Hutchinson 2008; Rubio et al. 1998). Sin embargo, entre los embera eyábida de Murindó, de Mutatá y de Chigorodó, los nombres de especies naturales aparecen más en los apodos que en los registros civiles ${ }^{4}$. Esto se debe probablemente a la influencia de la Iglesia y de los funcionarios de la Registraduría Nacional del Estado Civil. Uno de los niños que conocimos había sido registrado como Simónides, pero cuando cumplió un año fue nombrado Dodurru (do: río/ durru: avispa) porque se mantenía con rabia, igual que la avispa de río. Una niña se llama Arizapono porque su cabello es crespo como la flor (pono) del árbol Arizá. Otra jovencita se llamaba Pisuma wera, que significa literalmente hormiga hembra, porque las hormigas la picaron el día que nació en el bosque. En suma, la selección del nombre puede hacerse retomando el nombre de un fallecido, tomando un nombre en castellano que ningún conocido esté usando, estudiando las características físicas o de comportamiento del niño para seleccionar un nombre que las refleje, inventando una palabra que puede ser compuesta de otras que sí tienen significado o inventando una que simplemente suene bien. El nombre que aparece en el registro civil, ya sea en embera o en castellano, es el que usan los maestros en la escuela para dirigirse al niño o a la niña y es el que se emplea en todos los trámites ante las autoridades del gobierno. Si ese nombre está en embera, seguramente será usado como vocativo en la comunidad, pero si el nombre está en castellano es probable que la familia llame a ese niño o niña en la vida diaria con un nombre en lengua embera o con un apodo.

\section{La Protección de los Niños y las Niñas}

El análisis de las prácticas de protección de los niños y las niñas está relacionado con lo que hasta ahora hemos expuesto sobre los nombres personales. Nada más ajeno al pensamiento embera que la idea de una etiología endógena de las enfermedades o la idea de un proceso de incubación de estas; las enfermedades están en el exterior, bajo la forma de jais que tratan de penetrar el individuo, por eso hay que evitar que salgan del cuerpo del chamán o de los lugares de la naturaleza donde ellos habitan. De ahí que Arias Valencia y López Restrepo (2014) planteen que para los embera la salud es sinónimo de equilibrio entre el mundo terrenal 
y el mundo de los espíritus y de armonía con el orden cósmico. Las prácticas de protección y defensa toman el lugar que tiene la prevención en la medicina occidental.

Las familias tienen muchos recursos simbólicos para proteger a sus niños. Por ejemplo, después del nacimiento se entierra la placenta bajo el fogón, para que en el futuro el niño construya una buena casa y no se aleje de su madre, y se entierra el cordón umbilical bajo una mata de plátano para que tenga buenas cosechas.

En 1960, Reichel-Dolmatoff explicaba que cuando el niño embera del Chocó cumplía un año de edad, el chamán le entregaba una figura antropomorfa de madera que representaba el espíritu tutelar. Todavía se entregan espíritus, aunque no siempre a través de una talla en madera. En Santa María del Baudó, el jaibaná explica que la entrega de un espíritu es un "bautizo" que hace inoficioso el bautizo católico, porque el espíritu del niño ya queda protegido (Com. pers. Winston Andrés Abadía, 2015).

En Chibugadó, el chamán hacía un canto de jai para el recién nacido y volvía a los tres meses para practicar otra ceremonia que tenía como finalidad darle fuerza, impedir que le dieran infecciones o granos después de chuzarse y, si era una niña, para que no tuviera heridas antes de la llegada de la primera menstruación. Hoy en día esta ceremonia no se hace, pero sí se pinta al niño con jagua cuando cumple un mes de nacido. La pintura con jagua hace parte, en algunos lugares, de la ceremonia de asignación del nombre cuando el niño tiene aproximadamente un año (Issaccson 1993). Los embera dicen que la pintura "afina el cuerpo", fortalece la piel, libera al niño de los rayos y de los animales peligrosos, evita los granos y la caída del cabello con el sol y previene que el niño coja espíritus cuando cae por accidente de su casa. Losonczy (1986) ha indicado que la pintura negra de este fruto tiene la virtud de invisibilizar al sujeto, de esconder su rostro, de crear un anonimato voluntario y transitorio, que lo protege durante los ritos de paso o cuando afronta un enemigo exterior. Kondo (2015) ha mostrado que la decoración del cuerpo con diseños geométricos, usual en las curaciones chamánicas, es eficaz porque cambia la imagen de uno mismo e impide así que lo reconozcan los jais. Ulloa (1992) presenta un abanico más amplio de funciones de la pintura corporal: comunicarse con los jais, asustarlos, protegerse de ellos, enamorarlos, propiciar estados anímicos, embellecerse, fortalecer a los bebés y a las mujeres jóvenes, etc.

El bautizo católico también protege al niño, cierra su cuerpo y cuida el alma principal del ataque de otros seres sobrenaturales (Domicó et al. 2002). Como nos decía una mujer: "Sin bautizo se enferma mucho, le da gripa y cuando le da fiebre, es muy alta; todavía tiene diablo que se lo puede llevar cuando la mamá está recogiendo plátano y se queda solo en la casa o en el monte. Ese diablo viene con la forma de la mamá y cuando uno llega a la casa, el niño ya no está”. Un hombre sustentaba la idea del nombre como protector del alma principal de la persona diciendo que así como el ser humano tiene dos jaures (almas), de la misma manera tiene un nombre y un apodo, que se usa para evitar los maleficios y nos contaba que cuando él mismo sale de viaje por comunidades desconocidas, inventa cualquier nombre para presentarse, incluso puede decir que se llama Pakurú (árbol), para que cuando los jaibanás "sueñen" con el fin de hacerle una maldad, solamente vean el árbol y no lo puedan ver a él.

Otra manera de proteger al niño y de "darle suerte" es el nẽpoa, que muchos embera traducen al castellano como "ombligada", aunque ese no sea su significado literal. Este ritual le permite adquirir las capacidades o cualidades de otras especies, de las que se obtienen sustancias que pueden mezclarse con achiote (Bixa orellana) o con aguardiente y aplicarse en el ombligo, comerse, beberse o frotarse sobre el cuerpo. Esas preparaciones crean un vínculo personal con una especie natural que el sujeto no podrá consumir durante el tiempo de la ceremonia pues podría perder las facultades deseadas (Gálvez 1993). Para los niños se buscan animales que sean fuertes, veloces, buenos cazadores, buenos pescadores y hábiles para el cortejo; para las niñas se buscan animales que sean activos, que duerman poco y que sean muy trabajadores. Cuando uno ha sido ombligado con un pájaro, su alma (jaure) se queda en el cuerpo y cuando uno la necesita piensa en ella: "entonces ese jaure empieza a trabajar en uno".

El mito del saíno o pecarí (Tayassu tajacu) ilustra bien el efecto protector de la ombligada. Esta historia cuenta que un hombre que no conocía más mujeres que su madre, bajaba por el río cuando se encontró unas mujeres desnudas que resultaron ser saínos; al verlo, ellas se zambulleron en el agua, regresaron vestidas y lo invitaron a su mundo subterráneo. Allí tuvo que pelear con seis saínos que no toleraban que esas mujeres tuvieran marido y por eso la población de esta especie había disminuido. Las peleas, cuerpo a cuerpo, se debían dar en medio de unas fiestas, previo consumo de chicha de maíz. El hombre, que al principio no encontraba el lugar donde se iban a hacer esas fiestas y no escuchaba la música, tuvo que bañarse con una infusión de plantas para "poder ver y escuchar". Luego, para pelear con esos saínos que eran mucho más fuertes y grandes que él, llamó a todos los animales con los que su madre lo había ombligado: oso y tigre para que le dieran fuerza, pajaritos para correr, etc. Para llamarlos, le bastaba con concentrarse y recordar como brincaba, saltaba o corría cada animal. Fue así como pudo "enfrentar a los espíritus malos" con los cuales los saínos lo atacaron, y convertirse en esposo de una de esas mujeres y en jefe de los saínos (Domicó et al. 2002). 
La práctica del nẽpoa indica que los seres humanos pueden acumular un número amplio de almas de animales o de plantas, sin que corran el peligro de transformar su cuerpo al punto de perder su humanidad ${ }^{5}$. Coincidimos con Kondo (2015), cuando dice que los embera reconfiguran sus cuerpos tomando capacidades o cualidades particulares que pertenecían a otros conjuntos, sin necesidad de representar o consumir al individuo completo, bastando con usar alguna de sus partes. El alma o jaure sería esa síntesis de las cualidades esenciales de un ser vivo que pueden ser transmitidas a otro ser tras la muerte de su portador original. Los embera se protegen de los espíritus y enfermedades enviados por los chamanes enemigos o que vagan por el monte, pero no temen incorporar las almas de los animales silvestres, por el contrario, eso los vigoriza sin poner en riesgo su condición humana ${ }^{6}$. En todo caso, la "apertura" del cuerpo, que en la infancia favorecía la asimilación de cualidades de otras especies en beneficio de la construcción de la identidad personal, se vuelve en la edad adulta un riesgo: un cuerpo adulto debe ser un cuerpo "cerrado", con excepción del cuerpo de las mujeres que viven una apertura temporal durante la menstruación y el parto, y de los chamanes, cuyos cuerpos son permeables al ingreso y salida de sus espíritus aliados (Losonczy 1984).

\section{Conclusiones}

Los nombres personales de los embera son de varios tipos: la mayoría están compuestos de varias palabras que tenían referentes semánticos previos, algunos no significan nada, pero tienen un valor sonoro y otros aluden a las características del individuo o son tomados del castellano. La exigencia de no asignar a los niños o a las niñas nombres usados por otras personas vivas conocidas obliga frecuentemente a buscar nombres de difuntos, lo cual concuerda con la idea de la desagregación póstuma de la persona: mientras el cuerpo regresa a la naturaleza, las almas secundarias se transforman en agentes espirituales de la enfermedad y el infortunio y el alma principal regresa a la sociedad bajo la forma de un niño por nacer. Sin embargo, el ser humano se encuentra en un estado de construcción permanente. No basta con haber recibido un alma y un nombre. El embera recibirá durante su vida otras almas, a través del ritual nẽpoa, y otros nombres a través de los apodos. La asignación de un nombre, el bautizo católico, la pintura corporal y el ritual nẽpoa tienen funciones redundantes o complementarias: protegen el alma principal de la persona, la hacen invisible frente a los espíritus malignos y transmiten rasgos físicos y habilidades de otras especies naturales.

El número de nombres embera es muy alto y no cesa de crecer, en cambio el número de apellidos es muy pequeño y estable. El nombre individualiza porque no dice nada sobre las relaciones de parentesco del individuo nominado con otras personas, el nombre no es propiedad de grupos de filiación porque estos no existen, solamente hay parentelas con filiación bilateral y la memoria genealógica de las personas no va más allá de sus abuelos. De ahí que el conjunto de nombres esté siempre abierto para recibir aquellos que se inventan todos los días. Este rasgo diferencia la onomástica embera de la de grupos amazónicos donde los procesos de nominación están ligados a las diferencias entre los grupos y a su jerarquía interna (Pedroso 2019) o donde la transmisión de nombres de una generación a otra introduce al individuo a un universo estable desde el punto de vista geográfico y temporal (Vanzolini 2019). Uno podría pensar que el apellido embera sí clasifica porque inscribe al sujeto en una parentela, pero ese efecto clasificador es muy limitado puesto que hay muchas personas con el mismo apellido, al punto que no pueden encontrar ningún antepasado común; además, a raíz de la inestabilidad de las uniones matrimoniales, uno nunca sabe si el apellido de una persona es el de su padre o el de su madre. Lo que sí hace el apellido es identificar a la persona como embera frente a los mestizos y afrocolombianos de la región, pues aunque algunos están registrados con nombres en castellano nadie lleva a apellidos de origen hispánico.

La ontología está implícita en la lengua (Course 2010), por lo tanto, no sorprende que al estudiar la onomática embera hayamos encontrado vasos comunicantes entre el ser humano, las plantas, los animales, los accidentes geográficos y otras entidades naturales. La ontología embera no plantea esa diferencia entre un sujeto con capacidad de agencia y un objeto que carece de ella, propia de la ontología moderna, sino que reconoce una identidad interior entre todos los seres vivos, puesto que son personas y reconoce una diferencia exterior puesto que sus cuerpos son distintos. Sin embargo, no plantea una alteridad radical entre el cuerpo de individuos de diferentes especies. Para hacer del bebé embera un individuo de nuestra especie no hay que recluirlo cuando nace, ni prohibir a sus padres comer carne o pescado, salir a cazar, hacer la guerra o practicar el chamanismo, como hacen muchos otros pueblos amazónicos que pretenden crear con el recién nacido lazos de consanguinidad y fabricarle un cuerpo evitando asociaciones corporales con seres de otras especies (Vilaça 2002). Entre los embera sí hay una construcción social del cuerpo, pero esta no está dirigida a separarlo de otras especies. La transferencia de almas y cualidades de distintas especies naturales a los niños y niñas embera a través del ritual nẽpoa indica que la persona es el resultado de la contribución de diversas entidades humanas y no humanas. La afirmación que hace Tola (2005) sobre los toba de Argentina cabe para el caso embera: el cuerpo 
humano es el resultado de relaciones intersubjetivas con otros seres humanos y no humanos que permiten la circulación de distintas clases de extensiones corporales y, en consecuencia, la concepción binaria de la persona, como la suma de un cuerpo y de un alma, no puede estar más lejos de esta idea de persona como resultado de la conjugación de múltiples cuerpos y almas. La persona embera es además porosa, lo cual tiene un aspecto positivo porque permite incorporar cualidades de otras especies, pero también tiene un aspecto negativo pues expone al sujeto a múltiples agresiones mágicas. La “apertura” del cuerpo, que en la infancia favorecía la asimilación de sustancias externas en beneficio de la construcción de la identidad personal, se vuelve en la edad adulta un riesgo frente a los ataques de los espíritus enemigos: un cuerpo adulto debe ser un cuerpo "cerrado".

Agradecimientos: esta investigación fue posible gracias al año sabático concedido por la Universidad de Antioquia a la primera autora. El Instituto Colombiano de Bienestar Familiar le permitió a la profesora participar en un programa de atención a la infancia embera en el resguardo de Jaikerazabi, lo cual ayudó a comprender las prácticas de crianza. Expresamos también nuestra gratitud a las familias embera que compartieron con nosotros sus experiencias y sus saberes y a todos los evaluadores anónimos que contribuyeron con sus críticas a mejorar la versión inicial de este artículo.

\section{Referencias Citadas}

Aceto, M. 2002. Ethnic personal names and multiple identities in anglophone caribean speech communities in Latin America. Language and Society 31 (4):577-608.

Aguirre, D., R. González y M. Panchi 2013. Manual de Enseñanza y Escritura ẽbẽra-chami. Herramientas de Inclusión Social. Cartilla 6. Gerencia Indígena de Antioquia, Medellín.

Aguirre Licht, D. 2014. El Embera, Cómo se Habla la Lengua, Curiosidades de su Gramática. Imprenta Departamental de Antioquia, Medellín.

Arias Valencia, M.M. y A.D. López Restrepo 2014. Potes de Enfermedad entre los Embera. Patogenia y Cura. Editorial Universidad de Antioquia, Medellín.

Bellier, I. 1994. Los mai-huna. En Guía Etnográfica de la Alta Amazonía, Vol. 1 (Mai Huna, Yagua, Ticuna), editado por F. Santos y F. Barclay, pp. 1-180. Flacso, IFEA, Quito.

Bodenhorn, B. y G. vom Bruck 2006. "Entangled in histories". An introduction to the anthropology of names and naming. En The Anthropology of Names and Naming, editado por G. vom Bruck y B. Bodenhorn, pp. 1-30. Cambridge University Press, Nueva York.

Cayón, L. 2013. Pienso, Luego Creo. La Teoría Makuna del Mundo. Instituto Colombiano de Antropología e Historia, Bogotá.

Course, M. 2010. Of words and fog. Linguistic relativity and Amerindian ontology. Anthropological Theory 10 (3):247-263.

Descola, P. 1986. La Nature Domestique: Symbolisme et Praxis dans l'Écologie des Achuar. Editions de la Maison des Sciences de l'Homme, París.

Descola, P. 1996. Constructing natures. Simbolic ecology and social practice. En Nature and Society, editado por P. Descola y G. Pálsson, pp. 82-102. Routledge, Londres.

DANE [Departamento Administrativo de Planeación Nacional] 2005. Censo General. Bogotá.

De Matos Viegas, S. 2008. Pessoa e individuação: o poder dos nomes entre os Tupinambá de Olivença (sul da Bahia, Brasil). Etnográfica 12 (1):71-94.

Domicó, J.J., J.J. Hoyos y S. Turbay 2002. Janyama, un Aprendiz de Jaibaná. Instituto Colombiano de Antropología e Historia, Universidad de Antioquia, Medellín.
Duque, L.M., I.E., A. Gálvez, D. Herrera y S. Turbay 1997. Chajeradó, Río de la caña Flecha Partida. Impacto de la Explotación de Madera sobre un Grupo Embera del Atrato Medio Antioqueño. Colcultura, Santafé de Bogotá.

Gálvez,A. 1993. La Herencia del Pájaro Cuéndola. LaAlimentación entre los Indígenas Eyabida del Noroeste Colombiano. Memoria de Maestría en Antropología, Universidad de Montreal, Montreal.

Gálvez, A., N. Galeano y S. Turbay 2009. Los alimentos de la gente en los mitos embera. En Ecosistemas y Culturas, editado por J. Rosique y S. Turbay, pp.183-205. Imprenta Universidad de Antioquia, Medellín.

Gobernación de Antioquia 2014. Censo Indígena de Murindó. Gerencia Indígena, Medellín.

Gonçalves, M.A. 1992. Os nomes própios nas sociedades indígenas de terras baixas da América do Sul. Boletim Informativo e Bibliográfico de Ciências Sociais-BIB 33 (1):51-72.

Goulard, J.P. 1994. Los Ticuna. En Etnográfica de la Alta Amazonía. Vol. 1 (Mai Huna, Yagua, Ticuna), editado por F. Santos y F. Barclay, pp. 309-444. Flacso, IFEA, Quito.

Herrera, F. 2012. La evolución de las demandas indígenas sobre la tierra y las respuestas del Estado en Panamá. Quaderns-E $17: 44-59$.

Hutchinson, S. 2008. Reforestation Clean Development Mechanism Projects: The Case Study of the Ipeti-Emberá. Tesis de Maestría en Ciencias Ambientales. Universidad de Québec, Montreal.

Hugh-Jones, S. 2002. Nomes secretos e riqueza visível: nominação no noroeste amazônico Mana 8 (2):45-68.

Isacsson, S.E. 1993. Transformations of Eternity: On Man and Cosmos in Emberá Thought. Tesis de Doctorado, Departamento de Antropología Social, Universidad de Gotemburgo, Gotemburgo.

Kane, S.C. 1994. The Phantom Gringo Boat. Shamanic Discourse and Development in Panama. Smithsonian Institution Press, Washington DC.

Kondo, H. 2015. The skin as a surface of composition: The use of animal body parts and plants in various practices of Panamanian embera. Tipiti: Journal of the Society for the Anthropology of Lowland South America 13 (2):11-23. 
Kondo, H. 2016. Conflicto interétnico y autonomía indígena: Una historia corta de la Comarca Emberá-Wounáan. Cátedra 13:77-100.

Londoño Sulkin, C.D. 2017. Moral sources and the reproduction of the Amazonian package. Current Anthropology 58 (4):477-501.

Loewen, J.A. 1963. Chocó I: Introduction and bibliography. International Journal of American Linguistics 29 (3):239-263.

Losonczy, A.M.1984. Espace féminin. Espace masculin. Les indiens embera de Colombie. Les Cahiers du GRIF 29 (1):77-90.

Losonczy, A.M. 1986. Le destin des guerriers. Agression chamanique et agression guerrière chez les embera du Chocó. Journal de la Société des Américanistes LXXII:157-183.

Losonczy, A.M. 2006. Viaje y Violencia. La Paradoja Chamánica Embera. Universidad Externado de Colombia, Bogotá.

Martínez, H.E. 1989. Genealogía de los Indios Katíos de Dabeiba. Imprenta Departamental, Dabeiba.

Martínez, H.E. 1992. Diccionario Katío-Español, EspañolKatío. Imprenta Departamental, Dabeiba.

Pedroso, D.R. 2019. O Que Faz um Nome: Etnografía dos Kubeo do Alto Vaupés (AM). Tesis doctoral en Antropología Social, Universidad de São Paulo, São Paulo.

Reichel-Dolmatoff, G.1986. Desana. Simbolismo de los Indios Tukano del Vaupés. Procultura, Bogotá.

Reichel-Dolmatoff, G. 1960. Notas etnográficas sobre los indios del Chocó. Revista Colombiana de Antropología 9:73-158.

Rodríguez, G., N. Morales, D. Fernández y J.R. Aparicio 2015 Asuntos de Familia. Un Estudio Cualitativo sobre las Redes Sociales en el Embarazo y en el Parto en Panamá. Comarcas Embera-Wounan y Guna-Yala. Salud Mesoamérica IDB, Panamá.

Rosique-Gracia, J., A. Gálvez-Abadía, S. Turbay, N. Domicó, A Domicó, P. Chavarí, J. Domicó, F.A. Alzate, J. Fernando Navarro y S. Rojas-Mora 2020. Todos en el mismo pensamiento: las relaciones del pueblo embera con los sitios sagrados de los resguardos de Polines y Yaberaradó en Chigorodó (Antioquia). Tábula Rasa $36: 201-222$

Rubio, H., A. Ulloa, M. Rubio e Indígenas Embera 1998. Tras las Huellas de los Animales. Fundación Natura-OREWA-MMAInstituto Colombiano de Antropología, Bogotá.
Ruiz Serna, D. y C. Del Cairo 2016. Los debates del giro ontológico en torno al naturalismo moderno. Revista de Estudios Sociales 55:193-204.

Santos-Granero, F. 2012. Beinghood and people-making in native Amazonia. A constructional approach with a perspectival coda. Hau: Journal of Ethnographic Theory 2 (1):181-211.

Seeger, A., R. Da Matta y E. Viveiros de Castro 1979. A construção da pessoa nas sociedades indígenas brasileiras. Boletim do Museu National 32:2-19.

Smith, K. 2012. From dividual and individual selves to porous subjects. Taja, The Australian Journal of Anthropology 23:50-64.

Szulc, A. 2012. El poder de nominar. Los nombres de los niños y niñas mapuche como campo de disputa. Runa 33 (2):175-192.

Teodossopoulus, D. 2013. Embera indigenous tourism and the trap of authenticity: Beyond in-authenticity and invention. Anthropology Quaterly 86 (2):397-426.

Tola, F.C. 2005. Personas corporizadas, multiplicidades y extensiones: un acercamiento a las nociones de cuerpo y persona entre los tobas (gom) del chaco argentino. Revista Colombiana de Antropología 41:107-134.

Ulloa, A. 1992. Kipará. Dibujo y Pintura, dos Formas Embera de Representar el Mundo. Universidad Nacional de Colombia, Bogotá.

Vanzolini, M. 2019. The Name of the Relation. Making a Difference in Aweti Onomastics. Social Analysis 63 (2):102-121.

Velásquez Runk, J., C. Peña Ismare y T. Peña Conquista 2019. Animal transfer and transformation among the wounaan. Journal of Latin American and Caribbean Anthropology 24 (1):32-51.

Vilaça, A. 2002. Making kin out of others in Amazonia. The Journal of the Royal Anthropological Institute 8 (2):347-365.

Vilaça, A. 2011. Dividuality in Amazonia: God, the Devil, and the constitution of personhood in Wari' Christianity. The Journal of the Royal Anthropological Institute 17 (2):243-262.

Viveiros de Castro, E.B. 1986. Araweté: Os Deuses Canibais. Editorial Jorge Zahar, Río de Janeiro.

Viveiros de Castro, E. 1998. Cosmological deixis and Amerindian perspectivism. Journal of the Royal Anthropological Institute 4 (3):469-488

\section{Notas}

${ }^{1}$ Una reconsideración del concepto de autenticidad puede encontrarse en el análisis que hace Teodossopoulus (2013) de la manera como una comunidad embera de Panamá se representa a sí misma frente a los turistas.

${ }^{2}$ Con respecto a las escalas en la pronunciación encontramos en nuestra lista de nombres casos como los siguientes: (1) b,p: Bairubi y Baerupi; (2) d.t: Erutau y Erudau; (3) ch-s-ts: Chaibi y Tsaibi; Chiarizama y Tsarisa; Chanipuma y Saripuma; Chadiuma y Sariuma; (4) o,u: Oarichibi y Uarchabi; (5) ch, y: Charibi y Yadibi.

${ }^{3}$ Kane (1994) encontró entre los embera de Panamá que la tarea del chamán es escuchar el discurso ambiguo y contradictorio del paciente y resolver la situación alterando el sentido que tiene de sî mismo y de la realidad. Con la ayuda del canto, los cigarrillos, los aromas, las danzas y las bebidas, el chamán seduce a los espíritus y los pone al servicio de la curación y de la reacomodación de los individuos para que puedan ajustarse a las oportunidades y restricciones derivadas de una estructura social cambiante.
${ }^{4}$ En lengua embera nombre y apodo se dice igual: tru, por eso vale la pena tener en cuenta a Aceto (2002), quien advierte que en los estudios sobre onomástica cualquier nombre alternativo o usado adicionalmente al nombre oficial tiende a ser llamado apodo, lo cual se explica porque muchos investigadores provienen de culturas donde no es frecuente tener múltiples nombres. El autor diferencia los apodos de los nombres oficiales, de los nombres étnicos y de los seudónimos y los define a partir de las siguientes características: se añaden a los nombres oficiales; son dados generalmente en la infancia por otros niños o por familiares y amigos y permanecen más allá de la adolescencia; frecuentemente destacan características o estigmas físicos y sociales que el receptor no quisiera mostrar y, aunque uno mismo no escoge su apodo, termina autonombrándose con él; además, los apodos se derivan más de factores externos que de la fonética del nombre original.

${ }^{5}$ Entre los Wounaan de Panamá, Velásquez Runk et al. (2019) también encontraron esa transferencia de características 
virtuosas de los animales a los humanos a través del ombligo en el momento del nacimiento. Los autores la calificaron como una manera de aumentar o potenciar las condiciones de la persona humana y la opusieron a las metamorfosis de humanos en animales relatadas por los mitos donde hay una pérdida de la humanidad como consecuencia de una falta moral, una desobediencia o un comportamiento inapropiado.

${ }^{6}$ Los Embera consideran que muchas plantas, animales y seres que viven en las cabeceras de los ríos y en los bosques son seres sociales, tienen pensamientos, sentimientos, valores morales y capacidad para comunicarse, pero lo que distingue a los humanos es el consumo de sal y la prohibición del incesto y del canibalismo, como han mostrado Gálvez et al. (2009) al analizar las historias acerca de los burumiá, los bibidikomia y los carauta, antiguos enemigos de los embera, los relatos sobre los cimarrones que se escondieron en el bosque huyendo de los conquistadores españoles y los mitos sobre los yhaberara, seres sin ano que apenas huelen la comida. Cuando se dice que los seres no humanos son caníbales en realidad se está diciendo que ven a los humanos como presas de caza y no como personas. Lo mismo ocurre con los seres humanos que salen a cazar: ven a los animales como si estuvieran desprovistos de subjetividad, no los ven como gente, si fuera así, no los podrían consumir. 
